SOCRATES

\title{
SOCRATES 4 (synopsis of Cochrane reviews applicable to emergency services)
}

\author{
P Gilligan, M Shepherd, G Lumsden, H Law, J Brenchley, G Kitching, A Taylor, A Khan, J Jones, \\ D Hegarty
}

1: $\mathrm{n}$ this the fourth article of the SOCRATES series we present the second half of the reviews from the Cochrane Database of Systematic Reviews relating to respiratory medicine that the working party felt were of particular relevance to emergency medicine practitioners. The methods of our review and the rationale for forming the SOCRATES working party are as have previously been published.

\section{CORTICOSTEROIDS FOR ACUTE EXACERBATIONS OF COPD}

The treatment of acute exacerbations of COPD entails the reversal of bronchospasm, treatment of infection, and reduction of airway inflammation. The role of corticosteroids is evaluated in this review.

\section{Results}

Seven randomised controlled trials comparing corticosteroids with placebo were included in this review. All other treatment options were standardised. The outcome measures reported varied considerably between the papers. The most commonly reported outcome, the $\mathrm{FEV}_{1}$ between 6 and 72 hours after treatment, showed no statistically significant difference between the glucocorticoid and placebo treatment. Treatment with glucocorticoid did show a significant benefit in relation to treatment failure and quality of life, but these outcome measures were not reported systematically by the papers.

\section{SOCRATES says}

The current evidence suggests that a short course of corticosteroids may decrease the subsequent need for hospitalisation in some patients with exacerbations of COPD.

$\Delta$ Wood-Baker R, Walters EH, Gibson P. Corticosteroids for acute exacerbations of COPD. Cochrane Library. Issue 4. Oxford: Update Software, 2000.

\section{DOXAPRAM FOR VENTILATORY FAILURE} ATTRIBUTABLE TO EXACERBATIONS OF COPD

The emergency department treatment of patients presenting with exacerbations of COPD entails the administration of bronchodilators, corticosteroids, and carefully controlled supplemental oxygenation. Despite these measures, patients may go on to develop respiratory failure. This review assesses the potential role of the respiratory stimulant, doxapram, in these patients.

\section{Results}

Only three trials involving 127 patients were included in the review all of which were randomised controlled trials. Doxapram was marginally superior to placebo in preventing deterioration in blood gas indices. One small study suggested that doxapram and non-invasive ventilation were equally effective in terms of blood gas changes, although there were more deaths in the doxapram group.

\section{SOCRATES says}

The current evidence suggests that doxapram may improve blood gas indices in the short term. However, as experience of non-invasive ventilation techniques improves, the reliance upon doxapram is likely to become less.

A Greenstone M. Doxapram for ventilatory failure due to exacerbations of COPD. Cochrane Library. Issue 4. Oxford: Update Software, 2000.

\section{HYPERBARIC OXYGEN FOR CARBON MONOXIDE POISONING}

Poisoning with carbon monoxide (CO) remains an important cause of accidental and intentional injury worldwide. Several unblinded non-randomised trials have suggested that the use of hyperbaric oxygen ( $\mathrm{HBO}$ ) prevents the development of neurological sequelae. The objective of this review was to assess the effectiveness of HBO compared with normobaric oxgen (NBO) for the prevention of neurological symptoms in patients with acute $\mathrm{CO}$ poisoning.

\section{Results}

Three randomised controlled trials of HBO compared with NBO were included in the analysis and outcome data were available on 455 patients. The main outcome measure of interest was the prevalence of persistent symptoms at one month follow up.

\section{SOCRATES says}

There is no evidence that unselected use of HBO in the treatment of acute CO poisoning reduces the frequency of neurological symptoms at one month.

A Juurlink DN, Stanbrook MB, McGuigan MA. Hyperbaric oxygen for carbon monoxide poisoning. Cochrane Library. Issue 1. Oxford: Update Software, 2001.

\section{FIXED DOSE SUBCUTANEOUS LOW MOLECULAR WEIGHT HEPARINS COMPARED WITH ADJUSTED DOSE UNFRACTIONATED HEPARIN FOR VENOUS THROMBOEMBOLISM}

Venous thromboembolic disease (manifest as deep venous thrombosis of the legs and pulmonary embolus) has an incidence of $0.1 \%$ per year. Treatment with unfractionated heparin requires monitoring and dose adjustment. Low molecular weight heparins have the benefit that they cause less inter-patient variability in respect to a fixed dose and the theoretical advantage of a lower incidence of haemorrhagic complications.

\section{Results}

There were 14 radomised controlled trials, involving 4754 patients, included in the analysis.

\section{SOCRATES says}

Low molecular weight heparin can be used safely as standard treatment for the treatment of deep venous thrombosis. 
Further evidence is needed before this policy is accepted for patients with pulmonary embolic disease.

$\Delta$ Van den Belt AGM, Prins MH, Lensing AWA, et al. Fixed dose subcutaneous low molecular weight heparins versus adjusted dose unfractionated heparin for venous thromboembolism. Cochrane Library. Issue 1. Oxford: Update Software, 2001.

\section{CHEST RADIOGRAPHY IN ACUTE RESPIRATORY INFECTIONS IN CHILDREN}

Chest radiographs are frequently performed in the assessment of children with acute lower respiratory infections. However, the benefits are unknown.

\section{Results}

Only one paper involving 522 patients met the inclusion criteria of the review. The participants were ambulatory children aged between 2 months to 5 years. There were no statistically significant differences between those children undergoing chest radiography and the controls not being radiographed in relation to clinical recovery, subsequent hospital visit within four weeks, or subsequent admission to hospital.

\section{SOCRATES says}

The current evidence suggests that in ambulatory children, the routine use of chest radiography in the assessment of lower respiratory tract infection is unnecessary.

A Swingler GH, Zwarenstein M. Chest radiograph in acute respiratory infections in children. Cochrane Library. Issue 4. Oxford: Update Software, 2000.

\section{GLUCOCORTICOIDS FOR CROUP}

Croup is a common cause of upper airway obstruction in children. Although it is a self limiting illness, it can be a heavy burden on hospital resources, in particular in the emergency department. This review evaluates the role of glucocorticoids in the treatment of children with croup.

\section{Results}

Twenty four randomised controlled trials (2221 patients) comparing glucocorticoids with placebo were included in the review. A variety of glucocorticoid preparations and dose regimens were used. Use of glucocorticoids resulted in an improvement in the croup severity score at six hours. There was a decrease in the use of adrenaline (epinephrine) in the glucocorticoid treated group. In addition, there was a reduction in the duration of time spent in the emergency department (in those discharged after treatment) and in the duration of hospital stay in those admitted.

\section{SOCRATES says}

The current evidence supports the use of corticosteroids in the treatment of croup in children.

A Ausejo M, Saenz A, Pham B, et al. Glucocorticoids for croup. Cochrane Library. Issue 4. Oxford: Update Software, 2000.

\section{CONCLUSION}

We hope the reader has found our synopses relating to the reviews from the Cochrane Database of Systematic Reviews regarding respiratory medicine useful. In the next issue of the journal we will present reviews relating to head and spinal trauma.

\section{ACKNOWLEDGEMENTS}

We would like to thank Dr Richard Hardern and the staff of the Postgraduate Medical Library at the General Infirmary at Leeds for their support and technical advice in the preparation of this paper.

\section{Authors' affiliations}

P Gilligan, M Shepherd, G Lumsden, H Law, J Brenchley, G Kitching, A Taylor, A Khan, J Jones, Specialist Registrars in Emergency Medicine, The Yorkshire Rotation, UK

D Hegarty, General Practitioner, Leeds, UK

Funding: none.

Conflicts of interest: none declared.

Correspondence to: Dr P Gilligan, 1 Far Moss, Alwoodley, Leeds LS17 7NU, UK; hegartydeirdre@ireland.com 